\title{
Introduction
}

Equality has long been the rallying cry of liberal progressives and socialists. Finding expression in state intervention, redistributive taxation and comprehensive welfare services, the egalitarian agenda was implemented in one form or another throughout the world during the twentieth century. However, since the 1980s, an alternative view which posits that the quest for equality is both futile and counter-productive gained popularity. This view was actively promoted by market liberal critics of state intervention as an integral part of their efforts to promote a vigorous form of capitalist development which prioritizes deregulation, entrepreneurship and competition. Aided by the collapse of Soviet communism, a significant increase in international trade and the rise of individualism in many parts of the world, this approach found expression in the policies and programs of many Western governments as well as the International Monetary Fund (IMF) and the World Bank which required economic liberalization as a condition for aiding heavily indebted developing countries. In this climate, egalitarian ideals were vigorously denounced for undermining choice and harming economic growth. Instead of seeking to reduce inequality, it was argued that policymakers should focus on poverty alleviation, and ensure that the poor are able to compete in the market and enjoy a decent standard of living.

With the publication of bestselling books by scholars like Atkinson (2015), Piketty (2014), Stiglitz (2012, 2015) and Dorling (2017), these arguments have been challenged. These authors contend that inequality is not only morally reprehensible but has detrimental social, economic and political consequences. Inequality, they believe, undermines social solidarity, diminishes democratic participation, limits opportunities and impedes economic growth. As the social, economic and political costs of inequality have been recognized, these views have been widely endorsed. In a prescient speech in 2011, President Obama (2014) deplored the increase in inequality in American society claiming that it was undermining the country's democratic values. Surprisingly, some on the political right like Murray (2012) are also concerned that American society is fragmenting as a result of heightened inequality. International organizations such as the Organisation for Economic Co-operation and Development (OECD) (2015) and the World Bank (2016), which were not previously known for promoting egalitarian ideals, have also expressed concern about rising inequality. In an address to the annual meeting of the IMF and World Bank 
in the autumn of 2018, Christine Le Garde, the Fund's Managing Director, warned that inequality is threatening global financial stability, democracy and human rights. Media interest in the subject has also increased and many editorial commentaries now favor policies that will reduce inequality. Even The Economist magazine, which has long been committed to the promotion of market liberalism, recognizes that "growing inequality is one of the biggest social, economic and political challenges of our time" (2012, p. 3).

Calls for redistributive policies, which were previously dismissed, have now become commonplace. The OECD, IMF and World Bank have urged their member states to address the problem and promote what the World Bank $(2016,2018 b)$ calls 'shared prosperity' to ensure that those at the bottom end of the income distribution benefit equitably from economic growth. Most writers also recognize the need for human capital investments, particularly in technical skills so that workers will be better able to compete in a dynamic economy and earn remunerative wages which will not only raise living standards but reduce inequality. The promotion of employment opportunities and 'decent work' in the context of economic policies that promote shared prosperity is also prioritized. It is also recognized that gender disparities in education, pay and opportunities as well as discrimination against ethnic minorities, people with disabilities and immigrants should be addressed.

However, few writers make explicit reference to the role of social protection in promoting equality. One exception is Atkinson, who devoted a chapter of his book to the topic but it focuses primarily on the United Kingdom. Galbraith's (2016) book has a short section on the contribution of social security to reducing inequality in the United States. Although there is a sizeable literature on the extent to which the tax and benefit system in Western countries affects the distribution of income, few detailed studies of the way different types of social protection schemes reduce inequality are available. There is a need for a more comprehensive analysis of the redistributive impact of social protection and how it can more effectively contribute to social justice.

Although the term social protection has today largely replaced older terms like social security, income security and income protection, it still connotes a raft of income transfers that maintain or subsidize incomes to prevent or alleviate poverty. These schemes include social insurance, social assistance, universal allowances, employer mandates, tax credits and various poverty alleviation innovations from the Global South such as conditional cash transfers, nutritional supplements, food for work initiatives and micro-savings programs. While some do redistribute resources progressively, others do not and administrative inefficiencies, inadequate funding and even corruption impede their effectiveness. Obviously, social protection can have a greater redistributive impact if these problems are addressed and if these schemes are redesigned to promote egalitarian goals. It should be noted that the term 'scheme' will 
be used in this book in preference to 'program' or 'project' or 'cash transfers' and similar labels which are found in the literature. In places, it will be used interchangeably with the term 'program' which is more widely used in the United States.

Another reason for paying greater attention to social protection's role in reducing inequality is that these schemes are popular and institutionalized in many countries. Although social assistance has come under attack in Western countries such as Britain and the United States, it has expanded rapidly in developing countries over the last two decades. Many governments have introduced cash transfers that greatly augment the limited provisions adopted during colonial times and these initiatives have dramatically increased access to social protection in the Global South. There is a good deal of research to show that they have reduced the incidence of poverty but less information about their role in lowering inequality is available. This book seeks to fill this gap by examining social protection's redistributive impact and considering how its contribution to social justice can be enhanced.

Although the book is primarily focused on income inequality (which is a useful although imprecise proxy for inequality), gender, ethnic, spatial and other types of inequality are also discussed. Gender inequality and oppression are now at the forefront of public opinion because of recent events such as the advent of the \#Me Too movement in the United States, extensive media coverage of sexual violence in India and concern about the plight of young women fleeing gender oppression in Saudi Arabia. Speaking at the World Economic Forum in Davos in 2019, Canada's Prime Minister Justin Trudeau highlighted the problem of gender discrimination in education, employment and politics and called for a renewed international commitment to women's rights. Similarly, the spread of religious and racial hatred accompanying the rise of right-wing populist politics in many Western countries has drawn attention to the seriousness of the problem and the need for measures that counter its pernicious effects. Continued discrimination against migrants, people with disabilities and LGBTQ people also needs to be addressed. Although these issues are not the focus of this book, they are relevant to a discussion of how social protection can promote social justice. Certainly, a good deal has been written about the impact of social protection on women and their children, and on how conventional schemes should be modified to foster gender equality. The literature has also addressed the need for ethnic minorities, people with disabilities, indigenous people and those living in rural and especially remote areas to have equitable access to social protection.

This book contends that, if carefully designed and properly implemented, social protection can reduce inequality. Indeed, it shows that some schemes already function in this way and that in some countries social protection contributes significantly to social justice. However, it cannot be assumed 
that social protection invariably reduces inequality. Many schemes are not intended to redistribute progressively, and in many countries social protection comprises a haphazard and poorly coordinated collection of schemes which are inadequately funded, have limited coverage and are poorly administered. In some countries, they are deliberately used in a coercive and stigmatizing way and obviously have little, if any, redistributive impact. If social protection is to serve as an effective means of promoting social justice, these and similar problems must be addressed. Careful policy design, adequate funding and effective implementation will be needed to ensure that its potential is fully realized. The book hopes to show how this can be accomplished.

\section{OUTLINE OF THE BOOK}

The book is divided into three parts which deal firstly with an overview of the concept of inequality; next, the nature and features of social protection, and finally social protection, redistribution and social justice. Chapter 1 examines the way inequality has been defined from different disciplinary perspectives. Unidimensional approaches which focus on one type of inequality - such as income - are contrasted with multidimensional interpretations which include gender, ethnic, spatial, status and other disparities. Although these different dimensions have not been integrated into one conceptual schema, the chapter proposes that income inequality - which has been the focus of much of the literature - serves as a useful proxy for inequality since it correlates with other disparities. The chapter offers its own definition based on the notion of hierarchical differentiation but suggests that the antonym of inequality, namely equality, also needs to be considered. It notes that few writers have advocated for absolute equality and that most focus instead on equity or social justice to determine whether differences between people and groups can be legitimated on the grounds of fairness and equity. Reviewing different definitions of social justice, the chapter contends that in addition to legal equity and equity of opportunity, proactive policies which foster equity of results are required. These policies promote equality by reducing the 'distance' between those who are privileged and disadvantaged.

Chapter 2 reviews inequality in an historic context demonstrating both its antiquity and ubiquity. It shows that all human societies have been hierarchically differentiated but as a result of economic, social and political forces, it has taken different institutional forms at different times. However, it asserts that inequality is subject to policy change and recent inequality trends in both Western countries and the Global South are examined to illustrate this argument. After the 'Great Levelling' of the post-Second World War years, income and wealth inequalities rose sharply because of the adoption of market liberal policies. Although there are differences between countries, stark inequalities in 
income and wealth accompanied by declining opportunities for social mobility are now a pervasive feature of modern life. Reviewing explanations of the drivers of inequality, the role of economic and social factors are contrasted with policy decisions that shape market transactions in ways that favor those at the higher end of the inequality spectrum.

Chapter 3 asks how the problem of inequality can be addressed. It begins by making the case for egalitarianism which it defines as the advocacy of policies that promote the principles of social justice discussed in the book's first chapter. The role of redistribution in promoting an egalitarian agenda is examined and attention is paid to the views of those who vigorously oppose the use of redistribution for this purpose. These arguments are countered by a discussion of the benefits of egalitarianism, including its positive moral, social, political and economic effects. Although it is often argued that equality undermines freedom and harms economic growth, the chapter contends that egalitarian policies have many benefits. Policies to promote equality include the enforcement of legal rights, the realization of opportunities and the achievement of equitable outcomes. The chapter contends that they need to be linked to wider interventions that promote economic growth and raise standards of living.

The chapters in Part II of the book discuss social protection, beginning with Chapter 4, which offers a definition of the field and a descriptive account of the different types of social protection schemes. Reviewing different definitions, it argues that social protection can best be understood by identifying the different types of schemes that characterize the field today. They include social assistance, social insurance, universal allowances and employer mandates, among others. It also discusses the different sponsors of social protection, pointing out that governments are primarily responsible for funding and implementing these schemes but that a more pluralistic system involving nonprofits, local community groups and commercial providers has emerged, and that their contribution needs to be taken into account. It then examines the different types of social protection in more detail paying attention to both well-established and innovative poverty alleviation schemes which have proliferated in the Global South. The chapter concludes by briefly discussing different normative interpretations of social protection's role and functions which have been articulated in the academic literature, noting its own preference for a rights-based egalitarian approach.

Chapter 5 traces the historical evolution of social protection and its roots in traditional cultural familial and community obligations, almsgiving and the creation of mutual aid societies. It pays particular attention to the emergence of social assistance in Western countries when religious almsgiving was subjected to statutory authority. The Elizabethan Poor Law in England was particularly important and was subsequently adopted in other parts of the world. 
Next, it discusses the emergence of social insurance and related schemes and the idea that the state should be responsible for their funding and implementation. Known as the 'welfarists ideal' this approach transcended the residual character of social assistance to create comprehensive and universal programs that cover the population as a whole. Although widely implemented during the twentieth century, this ideal was forcefully challenged by market liberals who advocated the privatization of statutory schemes and their replacement with commercially managed mandatory retirement accounts. However, the privatization agenda was not fully realized and, in some cases, it has been reversed. These developments were accompanied by a commitment by international organizations such as the International Labour Organization (ILO), United Nations agencies and World Bank as well as many governments to promote social protection in the Global South. This resulted in a dramatic increase in the number and variety of schemes focused on poverty reduction so that almost half the world's population now has access to some form of social protection or another.

Chapter 6 discusses the goals and impact of social protection. It begins by examining social protection's impact on income and poverty, showing that many schemes make a positive contribution to raising the living standards of their beneficiaries. Research also reveals that these schemes reduce the incidence of poverty in society as a whole. Next, the chapter discusses social protection's impact on the economy. Contrary to the argument that social protection is economically damaging, it contends that it contributes to economic development by raising consumption, stimulating demand, promoting human capital formation, and fostering work and productive participation in the economy. In addition, social protection promotes long-term economic stability. All of these are prerequisites for sustainable economic growth. Social protection also has political goals which are seldom clearly stated but nevertheless influence decisions to introduce or expand these schemes. In addition to the electoral pressures exercised by interest groups, including the beneficiaries of these schemes, political elites and administrators play a significant role in shaping social protection. The chapter concludes by discussing social protection's wider social impact. Although it has often been claimed that social protection undermines traditional values, fosters crime and deviance, and weakens the social fabric, many studies find that it has positive social effects.

Part III of the book consists of two chapters that discuss social protection's contribution to social justice. Chapter 7 examines the dynamics of redistribution conceptually by asking how these schemes are funded and administered, and who benefits from them. It then reviews empirical evidence about their redistributive impact in different parts of the world. Because most studies are concerned with the redistribution of monetary resources, it focuses on three countries for which information about social protection's impact on women, 
ethnic minorities, people with disabilities and others is also available. These are Brazil, South Africa and the United States. In addition to redistributing resources to its beneficiaries, it is argued that social protection also contributes to a decline in inequality in society as a whole. The chapter concludes that social protection clearly has the potential to promote social justice and that governments should be proactively committed to using these schemes for this purpose.

Chapter 8 discusses steps that should be taken to enhance social protection's role in promoting equality. It begins by affirming the book's normative commitment to a rights-based egalitarian approach and proposes that a centralized social protection agency with authority and adequate resources be established to manage the social protection system and initiate a long-term planning process that coordinates the schemes sponsored by government agencies, nonprofits, community groups and commercial providers. It should ensure that the country's social protection system is appropriate to local economic and social conditions and take the lead in addressing the challenges facing social protection such as limited coverage, poor implementation, fragmentation, mismanagement, inadequate benefits and low funding - all of which undermine social protection's redistributive impact. Extending coverage so that the whole population is included should be given high priority. Universal rather than selective schemes should be prioritized and discriminatory practices that negatively affect women, ethnic minorities, immigrants and others must be eliminated. To promote social justice, governments should ensure that social protection is inclusive, adequate and efficient, and available to all as a right of citizenship.

Of course, the book's argument is not straightforward and it is recognized that achieving the goals of social justice through social protection depends on many complex factors, and especially a willingness on the part of political elites to adopt social protection policies that achieve these goals. It is also recognized that the book's argument will be challenged and even ridiculed by those who retain an implacable faith in the virtues of unfettered markets or in the virtues of customary beliefs and practices that sustain traditional hierarchical arrangements. But academics, policymakers and professionals who believe that the power and resources of the state can be harnessed to promote social justice should accept the challenge and contribute to the struggle ahead. 
James Midgley - 9781789905588 Downloaded from PubFactory at 04/26/2023 03:22:01PM via free access 